\title{
SPE 94950
}

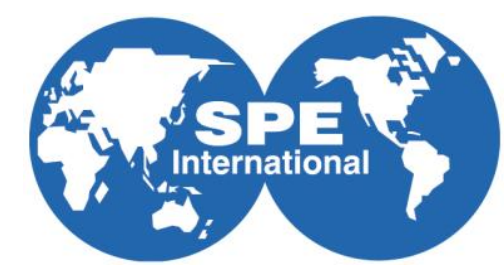

\section{Transient Two-Phase-Flow Model for Predicting Column Formation in Intermittent Gas Lift Systems}

Sarita Sandoval / PDVSA-INTEVEP, Luis Rojas Solórzano / USB, Sandro Gasbarri / UCV

Copyright 2005, Society of Petroleum Engineers Inc.

This paper was prepared for presentation at the 2005 SPE Latin American and Caribbean Petroleum Engineering Conference held in Rio de Janeiro, Brazil, 20 - 23 June 2005.

This paper was selected for presentation by an SPE Program Committee following review of information contained in a proposal submitted by the author(s). Contents of the paper, as presented, have not been reviewed by the Society of Petroleum Engineers and are subject to correction by the author(s). The material, as presented, does not necessarily reflect any position of the Society of Petroleum Engineers, its officers, or members. Papers presented at SPE meetings are subject to publication review by Editorial Committees of the Society of Petroleum Engineers. Electronic reproduction, distribution, or storage of any part of this pape for commercial purposes without the written consent of the Society of Petroleum Engineers is prohibited. Permission to reproduce in print is restricted to a proposal of not more than 300 pronibit. Proposal of not more than 300 words; illustrations may not be copied. The proposal must contain conspicuous Box 833836, Richardson, TX 75083-3836, U.S.A., fax 01-972-952-9435.

\begin{abstract}
The intermittent gas lift (IGL) method has experimented a continuous growth due to well depletion and so is expected from its technology. IGL is a periodic transient process with two major stages: firstly, a liquid column or slug is accumulated at the bottom of the well. Secondly, the slug is displaced by pressurized gas lift to the surface. Current models estimate the height of the fluid column based on single-phase behavior due to the lack of multiphase transient models. These models underestimate dramatically the column when the operating gas lift valve is located far away from the perforations. To improve this model a study focused on a twophase flow behavior during the accumulation stage is required. In order to achieve this objective a special multiphase flow facility was assembled and more than 200 steady and transient tests were run. Continuous and transient tests were performed with flow conditions and fluid properties selected from typical fields. The collected data allowed identifying the variables that govern the phenomena and establishing a methodology to determine the mixture density, pressure gradient and column's height. Since no previous correlation matched, a new correlation for transient hold up was generated using qualitative and dimensionless analysis. As part of the approach proposed here, time was included implicitly into the equations in order to reduce their complexity. The analysis showed that Reynolds's number, homogeneous liquid holdup and dimensionless viscosity govern the phenomenon. The model was validated with field data. The correlation applies to slug and churn flow patterns because those are the expected patterns for typical field conditions. The accuracy obtained with field data suggests applying this approach for designing and optimizing IGL installations.
\end{abstract}

\section{INTRODUCTION}

As reservoir pressure declines, continuous gas lift becomes extremely inefficient and must be replaced by intermittent gas lift in order to keep the injection gas liquid ratio (IGLR) economically profitable. Even though the injection GLR can be considerably reduced in these cases, IGL has not a high volumetric efficiency as an artificial lift method, and eventually the well must be abandoned or shifted to another artificial lift method because its operation is no longer profitable. Currently, more than 1300 wells in Maracaibo Lake are producing on IGL in fields where another lift methods cannot be used. This field is the largest offshore gas lift field in the world, with more than 5000 producing wells concentrated in one area. A search for alternatives to gas lift is an ongoing process, but due to the high formation gas-liquid ratio in these wells and the fact that a large gas lift system is already installed for a great number of wells, the economical implantation of any other artificial lift method is limited to a few wells even with latest technology. Hence, it is clear the important the research on IGL to extend the economical life of wells and increase its efficiency.

Focused on IGL, it is necessary to know all wells parameters for a satisfactory operation (pressure, temperature, fluids properties, column size, etc). One of the critical variable that influences the optimization of the method is the determination of the mixture density during the accumulation stage of the column. This accumulation stage is a transition process that cannot be neglected and is the subject of this study.

Current IGL simulation models simplify two-phase column with a single phase one made out of liquid. For this simplification there is not a gradient pressure variation neither flow pattern transitions along the column. For an appropriate design and optimization knowledge of the two-phase flow hydrodynamic and variables that govern the phenomenon is necessary.

The major objective of this work is to generate a mathematical model, allowing the prediction of mixture density, liquid holdup, the pressure gradient in the pipe and the real column size. This is useful for optimizing cycle times and the amount of gas required to lift the fluids and to improve the diagnostic and simulation software of IGL wells.

There are two general approaches dealing with multi-phase vertical flow: the first one is based on empirical models using the dimensional analysis; and the second is based on mechanistic models. In the oil industry, most of the two-phase 
flow studies in both approaches apply for steady state considering slippage ${ }^{1-8}$.

A related case is associated to the two-phase flow in artificial pumps lifting, where gas flows through a static column of liquid resting in the annulus space between tubing and casing. For this case there are special models to predict flow patterns and pressure drops ${ }^{9-11}$.

The first step in this research was to analyze field data and to try to approximate previous two-phase flow correlations with the data; however, a moderate success was achieved ${ }^{13}$.

For this reason, an experimental facility with typical field conditions was built in order to gather two-phase flow steady and transient data and to develop an appropriate and useful model.

\section{THEORETICAL BACKGROUND Intermittent Gas Lift}

Operating cycle of a well producing with IGL starts with liquid column formation at the bottom, and casing pressurization, until reaching the opening pressure of the operating valve. When the valve opens, gas goes into the tubing, and pushes the liquid column to the surface, while part of the liquid falls back. When the liquid slug reaches the separator, if pressure in the casing has dropped enough to close the operating valve then a new operating cycle begins with accumulation of gas in casing, and liquid in the tubing. Otherwise, injecting gas would flow until reaching the annulus valve closing pressure. Typical field magnitudes are API gravity 16-30, column heights from 200 to 800 feet and pressures of gas injection of 800-1200 psi. (Figure 1).

IGL technique offers the following variations:

- Conventional intermittent GL

- Intermittent GL with metallic plunger

- Intermittent GL with accumulation chamber (inserted and double packing)

- Conventional plunger Lift (natural flow)

- "PIGLIFT"

- Pump with gas chamber pump

Although this work may be used in the accumulation stage of all these methods, it focuses on conventional IGL. To see the relationships among the column, pressure, density and time; Caicedo ${ }^{12}$ gives a useful expression for single phase and no friction losses.

$Y_{\text {acum }}=Y_{\text {max }}+\left(Y_{o}-Y_{\text {max }}\right) \cdot e^{-\frac{5.615 \cdot \rho_{\text {liq }} \cdot J}{1440 \cdot A_{t}} \cdot T_{\text {accum }}}$ Eq. 1

Previous equation relates the column accumulated $\mathrm{Y}$ with the productivity index $\mathrm{J}$, reservoir pressure $\mathrm{P}_{\mathrm{r}}\left(\mathrm{Y}_{\max }\right.$ is a function if $\mathrm{P}_{\mathrm{r}}$ ), liquid density and accumulation time. This equation assumes single-phase flow. It is clear that two-phase flow changes the mixture density affecting the column height for any time, but it is to remark that this column has a gas fraction that should be taken out from liquid production.

\section{Average Mixture Properties}

Homogeneous model requires average determination of velocity and physical properties such as density and viscosity.

The mixture average velocity is the total volumetric flow rate divided by the cross sectional area pipe:

$$
V_{m}=\frac{q_{l}+q_{g}}{A}=v s l+v s g
$$

The mixture density can be expressed in terms of volume fraction (liquid holdup):

$$
\rho_{M}=\rho_{L} \cdot H_{L}+\rho_{G} \cdot\left(1-H_{L}\right) \quad \text { Eq. } 3
$$

The holdup is defined as the amount of gas that prevails on the liquid phase, it is calculated in terms of liquid and gas superficial velocities. The no slippage liquid holdup is given by:

$$
H_{L}=\frac{q_{l}}{q_{l}+q_{g}}=\lambda_{L}
$$

Eq. 4

\section{METHODOLOGY}

In this section, the test facility, its instrumentation and control system are described. The methodology applied as well as the dimensional analysis is also detailed.

\section{Test Facility}

A test loop to study IGL was built in the Artificial Lift Laboratory at PDVSA-INTEVEP. It consists mainly of a pumping section, an air compression section, liquid and air measurement equipment, a test section, a separation system (gas - liquid separator), a storage section and finally a control and data acquisition system, as detailed in Figure 2.

\section{Facility Description}

The liquid phase is stored in two tanks T-01 / T-02 (2000 Its capacity each one). The fluids are displaced by two pumps (P-01, P-02), with maximum capacities of 800 to $4500 \mathrm{BPD}$ and 50 to $900 \mathrm{BPD}$, respectively; both able to handle liquids with viscosities up to $54000 \mathrm{cSt}$. The suction and discharge pressures are monitored. Liquid mass flow, density and temperature are measured through two Coriolis meters, (FT01A and FT-01B ) with capacities of 170 to 600 BPD and 600 BPD to $6000 \mathrm{BPD}$, respectively.

The gas phase consists of air supplied by a double screw compressor with an open system. This machine can give a maximum flow of $500 \mathrm{Lts} / \mathrm{sec}$ (at standard conditions) and a maximum pressure of 230 psi. The tests were carried out working pressures of 100 psi. To measure the gas phase; orifice plates and a vortex meter FT-002 were used. Every run, one of those devices was selected depending on the rates to be measured.

The mixture zone (gas + liquid) is located at the bottom of the test section. The test section consists of a 20 m-pipe with a diameter of 2 inches. The section is divided in $8 \mathrm{~m}$ of conventional pipe and a 12-meter transparent pipe as the observation section. The first section is 400 -diameter long ( 8 $\mathrm{m})$ and guarantees a flow pattern totally developed. The measure section is distributed along the transparent pipe. The test loop has seven differential pressure transmitter sensors 
(DPT), installed approximately every two meters along the observation area. Two pressure transmitter sensors (PT) and two temperature transmitter sensors (TT) are located at the top and bottom parts of the test section. The fluids get into the vertical separator SEP-1 where the liquid and gas phases are separated. The liquid phase is returned to the storage tank creating a closed loop and the air is vented to the atmosphere. It is also possible to by pass the tanks and send the liquid directly to the pump intake.

The acquisition software was developed in LabVIEW ${ }^{\mathrm{TM}}$. Data was acquired at a rate of six readings per second. For the steady state flow tests, data was read for five minutes, giving a total of 1800 data records. On the other hand, between fifteen to twenty minutes were required for the transient tests because the complexity of the accumulation process.

In order to minimize errors and get consistent data all the instruments were calibrated independently in situ. This procedure is one of the most important when running experimental tests because the results and conclusions rely on the accuracy of this procedure. The proper operation of the complete loop (separator, valves, pumps, etc) was also checked. The calibration spans and their precision for each instrument are shown in appendix A.

\section{Working Fluids}

Experimental tests were carried out with mineral oils as liquid phase and air as gaseous phase. The mineral oils were the commercial Purolub ${ }^{\circledR}$ with two viscosities: $33 \mathrm{cP}$ and $311 \mathrm{cP}$. The rheological properties of used oils are presented in Table 1.

\section{Experimental Matrix}

The typical range of field conditions is shown in table 2 .

In order to perform representative test at lab it is necessary to perform scaling based on dimensional analysis considering the available fluids and pipeline dimensions in the laboratory. The analysis of field data generated an experimental matrix of 62 points. Each series of tests consists of two sets; the first one considering a continuous flow and the second one reproducing the accumulation process (transient flow); all representing 124 test points for each fluid and a total of 248 experimental tests.

The tests were carried out keeping a separator pressure of 5 psi. The flow pattern generated at each point was visually appreciated, and compared with the map of flow patterns of Barnea $^{3}$ and Gomez ${ }^{8}$.

\section{Dimensional Analysis}

The first step to generate the dimensionless numbers is to apply the theorem of Pi-Buckingham ${ }^{14}$, considering the complete list of the independent and dependent variables involved in the problem. For the transient two-phase-flow the following variables were considered:

$(d p / d z), v_{s l}, v_{s g}, \rho_{l}, \rho_{g}, \mu_{l}, \mu_{g}, \sigma, h, t, d, \varepsilon, g$.

The independent variable in this case is the pressure gradient $(d p / d z)$ and the dependent variables are: superficial liquid velocity $\left(v_{s l}\right)$, superficial gas velocity $\left(v_{s g}\right)$, liquid density $\left(\rho_{l}\right)$, gas density $\left(\rho_{g}\right)$, liquid viscosity $\left(\mu_{l}\right)$, gas viscosity $\left(\mu_{g}\right)$, fluid column height $(h)$, time $(t)$, pipe diameter $(d)$, pipe roughness $(\varepsilon)$ and acceleration of gravity $(g)$.

The number of variables is relatively high making the analysis very complex because of the number of combinations; therefore it is necessary to reduce some parameters whose influence in the process is negligible.

In view of the experimental low rates of gas and liquid the effect of the gas viscosity $\left(\mu_{g}\right)$ could be neglected. The influence of the pipe roughness $(\varepsilon)$ is reflected in the walls friction losses. For the special two-phase flow, where the gas flows through a column of liquid, the buoyancy forces have an appreciable effect, therefore, instead of considering the densities of gas and liquid independently, they can be expressed as a difference of densities $\left(\rho_{l}-\rho_{g}\right)$.

Bearing in mind the previous assumption, the group of variables to use in the dimensional analysis is the following:

$(d p / d z), v_{s l}, v_{s g},\left(\rho_{l^{-}} \rho_{g}\right), \mu_{l}, \sigma, h, t, d, g$.

Applying the theorem of Pi-Buckingham ${ }^{14}$ eight dimensionless groups are obtained:

$$
\begin{aligned}
& \text { Euler }=\frac{\Delta P}{\left(\rho_{l}-\rho_{g}\right) \cdot v_{s g}{ }^{2}} \\
& \lambda l=\text { Holdup }=\frac{v s g}{v_{s l}+v_{s g}} \\
& \frac{1}{\operatorname{Re}}=\operatorname{Re} \text { inolds }=\frac{\mu_{l}}{\left(\rho_{l}-\rho_{g}\right) \cdot v_{s l} \cdot d} \\
& \text { We }=\text { Webber }=\frac{\sigma}{\left(\rho_{l}-\rho_{g}\right) \cdot d \cdot v_{s l}^{2}} \\
& \text { Tiempo }^{*}=\frac{t \cdot v_{s g}}{d} \\
& h a \operatorname{dim}=\frac{h}{d} \\
& \frac{1}{F r}=\text { Froude }=\frac{g \cdot d}{v_{s l}^{2}} \\
& \mu a \operatorname{dim}=\frac{\mu_{l}}{\mu_{g}}
\end{aligned}
$$

Since oils have almost the same surface tension, an additional simplification in the amount of dimensionless number is obtained by considering We/Fr because this value is proportional to the surface tension ratio.

Finally, the dimensionless groups that will be applied to interpret the phenomenon are the following ones:

$$
H_{l}=f\left(\frac{\Delta p}{\left(\rho_{l}-\rho_{g}\right) \cdot v_{s g}{ }^{2}}, \frac{h}{d}, \frac{\mu_{l}}{\left(\rho_{l}-\rho_{g}\right) \cdot v_{s l} \cdot d}, \frac{t \cdot v_{s g}}{d}, \frac{v_{s l}}{v_{s l}+v_{s g}}, \frac{\mu_{l}}{\mu_{g}}\right)
$$




\section{EXPERIMENTAL RESULTS}

In this section the results will be analyzed by looking at the flow pattern maps. These charts determine the conditions where flow pattern transitions occur for oil 33cP-air and oil $311 \mathrm{cP}$-air. The analysis of the dimensionless numbers that govern the phenomenon will be discussed later on this paper.

\section{Flow Pattern Maps}

In Figures 3 and 4 the flow pattern maps for upward flow are presented: the maps were generated by "Flowpat" program of Gómez ${ }^{8}$. The $\mathrm{X}$ axis is the liquid superficial velocity and the $\mathrm{Y}$ axis is the gas superficial velocity.

To observe experimentally the transitions of the flow patterns, the liquid flow rate is held constant as the gas flow rate is being changed until a variation on the phase distribution along the pipe can be appreciated. The visual appearance of the flow patterns was registered and video recorded; then compared with predictions by $\mathrm{Gómez}^{8}$ predictions.

\section{3cP-Oil and Air Tests}

In Figure 3 the flow patterns map is presented for oil 33cPair, in a vertical pipe. The map presents both the experimental data and those reported by Gómez. Note that the experimental data and $\mathrm{Gómez}^{8}$ prediction are agree; however the experimental range does not cover the whole flow pattern maps; therefore all possible transitions paths are not appreciated. In these tests, intermittent (slug and churn) and bubble flow patterns were observed. The bubble-flow to slugflow transition is shifted to a lower value than predicted by Gómez $^{8}$ with a maximum difference of $0.094 \mathrm{~m} / \mathrm{s}$ in the superficial gas velocity. It is important to mention that the intermittent pattern was the most commonly observed.

\section{1cP-Oil and Air Tests}

In Figure 4 the flow patterns map is shown for oil $311 \mathrm{cP}-$ air in a vertical pipe. The predominant patterns are intermittent. The bubble-flow to slug-flow transition is obtained at lower superficial gas velocity than those predicted by $\mathrm{Gómez}^{8}$ with a maximum difference of $0.0186 \mathrm{~m} / \mathrm{s}$ in the superficial gas velocities. When observing the churn flow to the annular flow transition, it is clear that the Gómez's model ${ }^{8}$ does not match with the experimental data. Even though the experimental range was large enough to cover the churn flow to annular flow transition, according to Gomez's model, this transition was not reached in the tests.

It was observed that the intermittent flow zone decreases as liquid viscosities increases, because the viscosity and the surface tension hold the air in equilibrium inside the viscous liquid for more stressing conditions.

\section{MODEL DEVELOPMENT}

In this section will be discussed the development of the mathematical model that reproduces the liquid holdup (Hl) and the mixture density during the accumulation stage.

Analyzing the experimental data looking for relationships between dimensionless numbers, only 3 of these show a remarkable trend easy to correlate with the holdup. Then equation 6 can be reduced to:

$$
H l=f\left(\frac{\left(\rho_{l}-\rho_{g}\right) \cdot v_{s l} \cdot d}{\mu_{l}}, \frac{v_{s l}}{v_{s l}+v_{s g}}, \frac{\mu_{l}}{\mu_{g}}\right)
$$

The $\mathrm{Re}_{\mathrm{vsl}}$ number suggests that inertial effect, buoyancy and viscous forces control the phenomenon. For high Re values the inertial and buoyancy forces dominate the system's dynamics. For low Re values, the viscous forces govern the system. The liquid homogeneous fraction $(\lambda)$ indicates that gravity forces also affect the system; meanwhile the dimensionless viscosity will be useful for introducing explicitly the viscous effects.

Figure 5 shows, for both fluids, non-slippage liquid holdup $(\lambda)$ vs. Slippage holdup $(\mathrm{Hl})$ curves for several Revsl ranges. Note that the curves have a defined trend that can be fitted with a power law. Then, the general equation for the calculation of the $\mathrm{Hl}$ is the following:

$$
\mathrm{Hl}=\mathrm{a} \cdot \lambda \mathrm{l}^{\mathrm{b}}
$$

The coefficients $\mathbf{a}$ and $\mathbf{b}$ are obtained as a function of the natural logarithm of $\mathrm{Re}_{\mathrm{vsl}}$.

$$
\begin{aligned}
& a=d \cdot \ln \operatorname{Re}_{v s l}{ }^{2}+e \cdot \ln \operatorname{Re}_{v s l .}+f \\
& b=d^{\prime \prime} \cdot \ln \operatorname{Re}_{v s l .}{ }^{2}+e^{\prime \prime} \cdot \ln \operatorname{Re}_{v s l}+f "
\end{aligned}
$$

The parameters of these equations are also a natural logarithm function of the dimensionless viscosity.

It was verified that this model holds beyond the experimental viscosity range, at least giving reasonable physical results.

Figure 6 shows that, for viscosities ranging from 33 up to $311 \mathrm{cP}$, the comparison between the generated model holdup and the collected data experimentally, the prediction has a maximum deviation of $10,56 \%$. The corresponding error is specified in the Table 3, and the error analysis is described in appendix B.

The comparison between generated pressure gradient from the proposed model and the data obtained experimentally are shown in the Figure 7. The prediction has a maximum deviation of $15.28 \%$ and the value of E2 is $9.16 \%$. The gradient errors are tabulated in the Table 4.

\section{Large Scale}

Once the liquid holdup is determined with the proposed model, then the mixture density, the pressure gradient and the column height are calculated.

Real columns in the field are much higher than laboratory columns, and then the assumption of a void fraction and pressure gradient calculated with the average properties is not longer true. To solve this problem, the pressure profile must be calculated dividing the pipe in pressure or length increments and the pressure gradient is evaluated at local conditions (Hl, mixture density, temperature, pressure). The pressure profile accuracy improves as the number of sections increases.

Gasbarri and Moy's ${ }^{13}$ consider a methodology to calculate the column height. Appendix $\mathrm{C}$ specifies the modified algorithm that includes the proposed model. With this 
algorithm the column height and the average gradient of the whole pipe section can be obtained.

The developed model applies not only for the transient phenomenon but also can be used in steady state flow, with equivalent conditions as those conditions presented in IGL wells. The range application of the model is limited to slug and churn flow, since this study determined that these are the predominant flow pattern during the accumulation stage. The average relative error (E1) between the pressure gradient for steady state flow and the pressure gradient for transient flow was less than $1 \%$.

In order to calculate the total average gradient, the friction gradient is obtained applying the correlation of Churchill ${ }^{14}$, and added to the hydrostatic gradient. Then, the average column height is calculated knowing the mixture density and the pressure gradient.

\section{MODEL VALIDATION}

In order to validate the model, field data was collected. The parameters obtained were the total liquid flow rate, gas oil Ratio (GOR), accumulation time, cycle time, bottom flowing pressure inspection, bottom hole temperature, API gravity, gas specific gravity, water cut, tubing and casing diameter from selected wells.

Some wells have considerable uncertainty in gas measurements; the GOR values present high dispersion (at least $50 \%$ ), increasing the errors in the prediction of holdup and pressure gradients.

The pressure gradient calculated by the model has an average error of $0,09665066 \mathrm{psi} / \mathrm{pie}(33,58 \%)$, an absolute average error of $-0,09304966 \mathrm{psi} / \mathrm{pie}(40,07 \%)$, and a standard deviation of $0.10188521 \mathrm{psi} / \mathrm{pie}(34,44 \%)$.

Pressure gradient trend curves as a function of liquid volume, API gravity, GOR and water cut were analyzed in order to define the application range of the model. The following ranges are recommended as valid for the model: liquid rates (10-500) BPD, water cut (1\%-76\%), GOR (1009500) SCF/STB and oil gravity (15-35) ${ }^{\circ} \mathrm{API}$.

After defining the application range of the proposed model, it was compared with the methodology applied in the "ISIS ${ }^{\mathrm{TM}}$ Simulator" whose calculations to determine the column height do not consider the gas effects.

Table 5 shows the comparison of the real gradient (obtained from a pressure inspection) with the gradient calculated with the previous and the new model, having errors of $397 \%$ and of $7 \%$ respectively. Obviously the proposed model adjusts much better to the field conditions.

In the ISIS ${ }^{\mathrm{TM}}$ simulator, the holdup is compensated by the column height only when the operating valve is close to the perforations. Otherwise, the simulator may give results wide different from the field, particularly oil and gas production due to column height calculations.

\section{CONCLUSIONS AND RECOMMENDATIONS}

A two-phase flow model to predict the behavior during the accumulation stage in the Intermittent Gas Lift process has been developed. The model is based on steady and transient laboratory tests, and validated with limited field data. The results aim to the following conclusions:
1..The transient two-phase flow phenomenon can be represented as a series of time step estimations of steady state flow with equivalent conditions.

2.The two-phase flow phenomenon during the accumulation stage within the conditions found in this study is governed by three dimensionless numbers: $\operatorname{Reynolds}\left(\mathrm{v}_{\mathrm{sl}}\right)$ number, liquid homogenous holdup $(\lambda \square)$ and the dimensionless viscosity ( $\mu \square \operatorname{dim}$ ). The developed model is properly defined by one power law equation of these dimensionless numbers.

3 . The proposed model improves greatly fluids column and production predictions of several wells in Lake Maracaibo.

4. The predominant flow-patterns during the accumulation stage found under field conditions for IGL is slug and churn flow; i.e., the model here developed is suitable to apply in these conditions.

5. Gomez's flow pattern maps were found appropriate for two-phase flow when considering liquids with viscosities lower than $100 \mathrm{cP}$.

In order to further the understanding of the phenomenon and to improve the modeling capabilities, the following recommendations are given:

1. The proposed model for IGL in the following range: liquid rates (10-500) BPD, water cut (1\%-76\%), GOR (1009500) SCF/STB and oil gravity (15-35) ${ }^{\circ} \mathrm{API}$.

2 . The model could be improved by performing one extra low liquid viscosity experiments to verify the accuracy of the model. It is also recommended to evaluate the model in conditions with emulsions.

3. Future studies in multiphase flow predictions should consider and include as much as possible, the results from experiments performed in this research.

\section{Nomenclature}

API = Gravity of the crude oil

$\mathrm{d}=$ Diameter of the tubing $(\mathrm{ft})$

$\mathrm{g}=$ Gravity

GOR= Gas Oil Ratio

Grad $=$ Gradient of pressure (psi/ft)

Gradrealassum $=$ Real pressure gradient assumed $(\mathrm{psi} / \mathrm{ft})$

$\mathrm{H}=$ Height of the liquid column in the experimental data ( $\mathrm{ft}$ )

$\mathrm{N}=$ Number of liquid column segments

$\mathrm{P}=$ Pressure $(\mathrm{psi})$

$\mathrm{P}(\mathrm{i}, \mathrm{j})=$ Pressure average of each segment (psia)

$\mathrm{P} 1{ }^{\prime}=$ Pwf , bottom-hole pressure in the experimental data (psi)

$\mathrm{P} 2$ ' $=$ Pwh, surface pressure in the experimental data (psi)

Qg = Gas flowrate (scfd)

$\mathrm{Ql}=$ Flowrate $($ stkbpd $)$

$\mathrm{T}=$ Temperature $(\mathrm{F})$

$\mathrm{T} 1=$ Average temperature of the segment $\left({ }^{\circ} \mathrm{F}\right)$

$\mathrm{T} 2=$ Average temperature of next segment $\left({ }^{\circ} \mathrm{F}\right)$

$\mathrm{v}_{\mathrm{sl}}=$ Superficial velocity of liquid $(\mathrm{ft} / \mathrm{s})$

$\mathrm{v}_{\mathrm{sg}}=$.Superficial velocity of gas $(\mathrm{ft} / \mathrm{s})$

$\rho \square \square \square . .=$ Density $(\mathrm{lbm} / \mathrm{ft} 3)$

$\mu .=$ Viscosity $(\mathrm{cP})$

$\sigma \square \square \square . .=$ Surface tension $($ dyne $/ \mathrm{cm})$ 
$\Delta \mathrm{P}=$ Pressure variation (psia)

\section{Subscripts}

$\mathrm{g}=\mathrm{Gas}$

$\mathrm{i}=$ Local index of segment

$\mathrm{j}=$ Index of iterations made by segment

$\mathrm{L}=$ Liquid

$\mathrm{M}=$ Mixture

$\mathrm{S}=$ Slip

seg $=$ Segment

\section{ACKNOWLEDGEMENTS}

Autors,thanks to the laboratory personnel: Guillermo Lombano, Pedro Gonzalez, Ramon Cabello, Victor Terán, and to Sergio Caicedo, Leonardo Suarez for their technical support.

\section{REFERENCES}

1. Taitel, Y. Barnea, D. and Duckler, A. E. (1980) "Modeling Flow Pattern Transition for Steady Upward Gas-Liquid Flow in Vertical Tubes", AIChE Journal, Vol 26, N 3, pp. 345-354.

2. Fernandes, R. C., Semita, R. and Duckler, a. E. (1983) "Hydrodynamic Model for Gas-Liquid Slug Flow in vertical Tubes", AIChE Journal, Vol 29, $\mathrm{N}^{\circ} 6$, pp. 981-989.

3. Barnea, D., Shoham, O. and Taitel, Y. (1985) "Gas Liquid Flow in Inclined Tubes: Flow Pattern Transition for Upward Flow", Chem. Eng. Sci., Vol 40, pp. 131-136.

4. Sylvester, N. A (1987) Mechanistic Model for Two-phase Vertical Slug Flow in Pipes. Transactions of the ASME, Vol. 109, pp. 206-213, December.

5. Alves, I. N., Caetano, E.F., Minami, K. and Shoham, O. (1991) "Modeling Annular Flow Behavior for Gas Wells", SPE Production Engineering, pp. 435-440.

6. Ansari, A. M., Sylvester N. D., Sarica, C., Shoham, O. And Brill, J. P. (1994) "A Comprehensive Mechanistic Model for Upward Two-Phase Flow in Wellbores", SPE Production \& Facilities J. pp. 142-152.

7. Felizola, H.; Shoham, O. (1995) "A Unified Model for Slug Flow in Upward Inclined Pipes". ASME J. Energy Resources Technology. Vol. 117, pp. 1-6.

8. Gomez, L., Shoham, O., Schmidt, Z.,Chokshi, R., Brown, A., and Northug, T. (1999) "A Unified Mechanistic Model for TwoPhase Flow in Wellbores and Pipelines", presented bat the SPE 74th Annual Meeting, Houston, pp.1-11.

9. Hasan, A.; Kabir, C.; Rahman, R. (1988) "Predicting Liquid Gradient in a Pumping-Well Annulus". SPE, Production Engineering. February.

10. Papadimitriou, D; Shoham, O. (1991) "A Mechanistic Model for Predicting Annulus Bottomhole Pressures in Pumping Wells". SPE 21669. Production Operations Symposium, Oklahoma City. April 7-9.

11. Persen, L.; Podio, A.; Rhouma, T. (1992) "A Fundamental Study of two phase Flow in a Vertical Wellbore Annulus. Multiphase Flow in Wells and Pipelines" (ASME). FED-Vol. 144, pp. 1-26.

12. Caicedo, S; (2001). "Estimating IPR Curves in Intermittent Gas Lift Wells From Standard Production" Tests. SPE 69403. Production Operations Symposium, Buenos Aires - Argentina City. March 25-28.

13. Moy ,S..and Gasbarri , S,..”A Methodology to determine the Liquid Column Height of Intermittent Gas Lift Wells". Petroleum Society's Canadian International Petroleum Conference 2002, Canada, June 11 - 13, 2002.
14. Alarcon, G. (1992) "Flujo de dos fases", Facultad de Ingeniería de la Universidad de los Andes, Escuela de Ingeniería Mecánica.

\section{APPENDIX A}

\section{Calibration of Instruments}

Table of the calibration ranges and precision of the instruments used in the experimental bank is presented.

\begin{tabular}{|c|c|c|c|}
\hline TAG & Description.ף & Calibration Range & Precision \\
\hline PT-003 & Pressure of discharge of the pump & $0-1103 \mathrm{Kpa}$ &.$+-0.1 \%$ span \\
\hline TT-001 & Temperature / Liguid & $10-80^{\circ} \mathrm{C}$ & $\begin{array}{c}.+/-0.1^{\circ} \mathrm{C} \quad+/- \\
0.02 \% \text { span }\end{array}$ \\
\hline FT-01A & Measurement of Masico Flow ף & $0-9000 \mathrm{Kg} / \mathrm{h}$ &.$+-0.50 \%$ \\
\hline AT-01A & Density of Liquido & $0-1500 \mathrm{Kg} / \mathrm{m} 3$ &.$+/-0.0005 \mathrm{~g} / \mathrm{cc}$ \\
\hline FT-002 & Mensuration of Flow Gas (Vortex) & $14.16-424.75 \mathrm{ACMH}$ & \\
\hline DPT-003 & Mensuration of Flow Gas (DPT) & $0-250$ in $\mathrm{H} 2 \mathrm{O}$ &.$+/-0.075 \%$ span \\
\hline TT-007 & Temperature / Gas & $10-50^{\circ} \mathrm{C}$ & $\begin{array}{c}.+/-0.1^{\circ} \mathrm{C}{ }^{+/-} \\
0.02 \% \text { span }\end{array}$ \\
\hline PT-005 & Pressure of Supply Gas & $0-1378.9 \mathrm{Kpa}$ & $++/-0.1 \%$ span \\
\hline DPT-008 & Level separator & $0-100$ in $\mathrm{H} 2 \mathrm{O}$ &.$+/-0.075 \%$ span \\
\hline PT-007 & Pressure Left Separator & $0-100$ Psi &.$+/-0.1 \%$ span \\
\hline PT-002 & Pressure Point Injection of Gas & $0-100$ Psi &.$+-0.1 \%$ span \\
\hline PT-004 & Pressure Point Injection of Liquid & $0-100$ Psi &.$+-0.1 \%$ span \\
\hline PT-001 & Pressure of suction of the pump & $0-689.5 \mathrm{Kpa}$ &.$+/-0.1 \%$ span \\
\hline DPT001A & Level in the tank. & $0-120$ "H2O &.$+/-0.075 \%$ span \\
\hline DPT-501 & \multirow{10}{*}{ Instruments area observation. } & $0-200$ in $\mathrm{H} 2 \mathrm{O}$ &.$+-0.075 \%$ span \\
\hline TT-502 & & $0-100^{\circ} \mathrm{C}$ & $\begin{array}{c}.+/-0.1^{\circ} \mathrm{C} \\
0.02 \% \text { span }\end{array}$ \\
\hline DPT-503 & & $0-1000$ in $\mathrm{H} 2 \mathrm{O}$ &.$+-0.075 \%$ span \\
\hline PT-504 & & $0-100 \mathrm{Psi}$ & \\
\hline DPT-502 & & $0-200$ in $\mathrm{H} 2 \mathrm{O}$ &.$+/-0.075 \%$ span \\
\hline DPT-605 & & $0-150$ in $\mathrm{H} 2 \mathrm{O}$ &.$+-0.075 \%$ span \\
\hline DPT-606 & & $0-200$ in $\mathrm{H} 2 \mathrm{O}$ &.$+-0.075 \%$ span \\
\hline DPT-604 & & $0-150$ in $\mathrm{H} 2 \mathrm{O}$ & .t- $0.075 \%$ span \\
\hline DPT-603 & & $0-150$ in $\mathrm{H} 2 \mathrm{O}$ &.$+-0.075 \%$ span \\
\hline TT-600 & & $0-100^{\circ} \mathrm{C}$ & $\begin{array}{c}.+/-0.1^{\circ} \mathrm{C} \quad+/- \\
0.02 \% \text { span }\end{array}$ \\
\hline
\end{tabular}

\section{APPENDIX B}

Statistical parameters used to evaluate the pattern. 1. Parameters of percentage error:

$$
\begin{aligned}
& \text { eri }=\frac{H l(\text { calculado })-H l(\text { medido })}{H l(\text { medido })} \\
& \text { eri } 2=\frac{\text { Grad. }(\text { calculado })-\text { Grad. }(\text { medido })}{\text { Grad.(medido })} \\
& E 1=\left[\frac{1}{N} \sum_{i=1}^{N} \text { eri }\right] \cdot 100 \\
& E 2=\left[\frac{1}{N} \sum_{i=1}^{N} \mid \text { eri } \mid\right] \cdot 100 \\
& E 3=\sum_{i=1}^{N} \sqrt{\frac{(\text { eri }-E 1)^{2}}{N-1}}
\end{aligned}
$$

Eq. b-1

Eq. b-4

Eq. b-5 
2. Error parameters in the $\mathrm{Hl}$ and gradient.

$$
\begin{aligned}
& e i=H l(\text { calculado })-H l(\text { medido }) \\
& e i 2=\text { Grad.(calculado })- \text { Grad.(medido })
\end{aligned}
$$$$
\text { Eq. b-6 }
$$

$$
\begin{aligned}
& E 4=\left[\frac{1}{N} \sum_{i=1}^{N} e i\right] \\
& E 5=\left[\frac{1}{N} \sum_{i=1}^{N}|e i|\right] \\
& E 6=\sum_{i=1}^{N} \sqrt{\frac{(e i-E 4)^{2}}{N-1}}
\end{aligned}
$$

Where E1 represents the percentage average error, E2 the absolute percentage average error, E3 is the standard deviation, E4 is the average error, E5 is the absolute average error, E6 is the standard deviation. The percentage absolute average error is considered a suitable parameter for evaluating of prediction a correlation's.

\section{APENDIX C}

\section{Methodology to Calculate the Column Height}

1. Define the quantity of segments to divide the column of liquid inside the production tubing.

2. Calculate the variation of pressure for segment. This value will be a constant in all the segments and iterations.

$$
\Delta P_{s e g}=\frac{P_{w f}-P_{w h}}{N}
$$

Eq. c-1

3. The pressure average for each segment will be used to calculate the fluid properties.

For the first pressure segment, $\mathrm{i}=1$

$$
P(i, j)=P_{w f}+\frac{\Delta P_{s e g}}{2}
$$

For the rest of the pressure segments, $i \neq 1$

$$
P(i, j)=P_{w f}-i . \Delta P_{\text {seg }}+0.5 . \Delta P_{\text {seg }}
$$

Eq. c-3

3. As a first approximation, assuming an average pressure gradient, the level of the fluids column may be estimated.

$$
\text { Length }_{\text {assume }}=H-\left(\frac{P_{w f}-P_{w h}}{\text { Grad }_{\text {real__assume }}}\right)
$$

In order to estimate the average temperature for each section, let's assume equal pressure gradient for all segments and estimate thelength of the segments (ft).

$$
\Delta \text { Zassume }=\frac{H-\text { Lenght assume }}{N}
$$

5. Calculation of the temperature average for section $\left({ }^{\circ} \mathrm{F}\right)$.

$$
\text { Where } \mathrm{i}=1
$$

Where $\mathrm{i} \neq 1$

$$
T 1(i, j)=T_{w f}
$$

Eq. c-6

$$
\begin{array}{cc}
T 1(i, j)=T 2(i-1, j) & \text { Eq. c-7 } \\
T 2(i, j)=T 1(i, j)-\frac{\Delta Z_{\text {assume }}}{H}\left(T_{w f}-T_{w h}\right) & \text { Eq. c-8 } \\
T(i, j)=0.5 .(T 1(i, j)+T 2(i, j)) & \text { Eq. c-9 }
\end{array}
$$

6. Calculation of the properties of the fluids starting from the data of production of liquid and gas, wellhead pressure charts (times of cycle), dynamic registrations of pressure in the well, analysis PVT to bottom conditions and surface.

7. With $\operatorname{Re}\left(\mathrm{v}_{\mathrm{sl}}\right), \lambda 1$, liquid viscosity; calculate $\mathrm{Hl}$, density of mixture from the proposed model.

8. With the previous properties, calculate gradient of pressure for this section.

$$
\frac{\Delta P}{\Delta Z}=\text { Grad.hidrostático }+ \text { Grad } \text {. fricción }
$$

9. Calculation of the variation of the height average for segment.

$$
\Delta Z=\frac{\Delta P_{\text {Seg }}}{\left(\frac{\Delta P}{\Delta Z}\right)}
$$

Eq. c-11

10. Calculation of the height average of each segment from the place where the pressure $\mathrm{P} 1$ was measured.

For the first iteration one has:

$$
Y(i, j)=\frac{\Delta Z}{2}
$$

Eq. c-12

And for the following iterations:

$$
Y(i, j)=Y(i-1, j)+0.5 \cdot \Delta Z_{\text {calc }}(i-1, j)+0.5 \cdot \Delta Z_{\text {calc }}(i, j)
$$

Eq. c-13

11. Calculation of the error of the variation of the supposed height and the variation of the calculated height.

$$
\text { Error }=a b s\left(\frac{Y(i, j)-Y(i, j-1)}{Y(i, j)}\right)
$$

Eq. c-14

If the error is less than Tolerance (1\%) then value of the variation of the height for the next iteration, is the calculated one and so on, until obtaining tolerance. This becomes for each one of the segments in which it is divided the production pipe until obtaining the height average.

12. Calculation of the average of the gradient of pressure in the analyzed column of fluid. 


$$
\frac{\Delta P}{\Delta Z}=\frac{P_{w f}-P_{w h}}{\operatorname{Altura}(i, j)}
$$

Eq. c-15

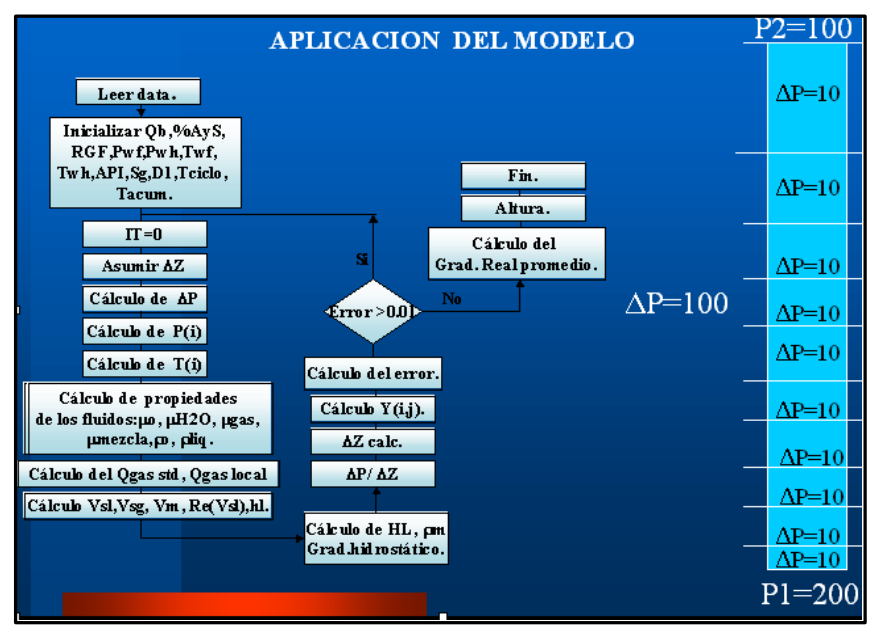

Fig. c-1. Proposed algorithm

\section{TABLES}

Table 1. Properties of the used oils

\begin{tabular}{|c|r|c|}
\hline Oils / Properties & $\begin{array}{c}\text { Purolub } \\
\mathbf{4 6}\end{array}$ & $\begin{array}{c}\text { Purolub } \\
\mathbf{1 5 0}\end{array}$ \\
\hline Density $\rho\left(\mathrm{Kg} / \mathrm{m}^{3}\right)$ & 854.8 & 875.6 \\
\hline Viscosity $\mu(\mathrm{cP}), 22^{\circ} \mathrm{C}$ & 33 & 311 \\
\hline $\begin{array}{c}\text { Superficial tension } \\
\sigma(\text { dynes } / \mathrm{cm})\end{array}$ & 29 & 31.4 \\
\hline
\end{tabular}

Table. 2. Range of the field variables

\begin{tabular}{|c|c|c|l|}
\hline Qlíquid & 20 & 300 & BPD \\
\hline RGL & 200 & 6000 & spc/Bls \\
\hline d & 2 & 3 & Pulgadas \\
\hline Pmin & 30 & 60 & Psig \\
\hline Pmáx & 100 & 400 & Psig \\
\hline API & 15 & 28 & API \\
\hline Viscosity liquid & 1 & 300 & Cps \\
\hline
\end{tabular}

Table. 3. Calculation errors of the liquid fraction, $\mathrm{HI}$

\begin{tabular}{|c|c|c|c|c|c|}
\hline E1 & E2 & E3 & E4 & E5 & E6 \\
\hline $2.13 \%$ & $7.75 \%$ & $10.56 \%$ & 0.00603 & 0.02624 & 0.04006 \\
\hline
\end{tabular}

Table.4. Calculation of the gradient of pressure (errors).

\begin{tabular}{|c|c|c|c|c|c|}
\hline E1 & E2 & E3 & E4 & E5 & E6 \\
\hline$-0.60 \%$ & $9.16 \%$ & $15.28 \%$ & $-0.00408 \mathrm{Ps}$ sipie & $0.0132 \mathrm{Ps}$ i/Pie & $0.01859 \mathrm{Ps}$ i/Pie \\
\hline
\end{tabular}

Table. 5. Comparison of the real gradient vs. the calculated gradient in the Well A1.

\begin{tabular}{|c|c|c|c|c|c|}
\hline Well & $\begin{array}{c}\text { Gradient of } \\
\text { real pressure }\end{array}$ & $\begin{array}{c}\text { Calculated } \\
\text { gradient / } \\
\text { previous } \\
\text { method }\end{array}$ & $\begin{array}{c}\text { Calculated gradient / } \\
\text { proposed model }\end{array}$ & $\begin{array}{c}\text { E2 previous } \\
\text { method }\end{array}$ & $\begin{array}{c}\text { E2 } \\
\text { proposed } \\
\text { method }\end{array}$ \\
\hline A1 & 0.076579 & 0.380242 & 0.070843765 & $397 \%$ & $7 \%$ \\
\hline
\end{tabular}

FIC
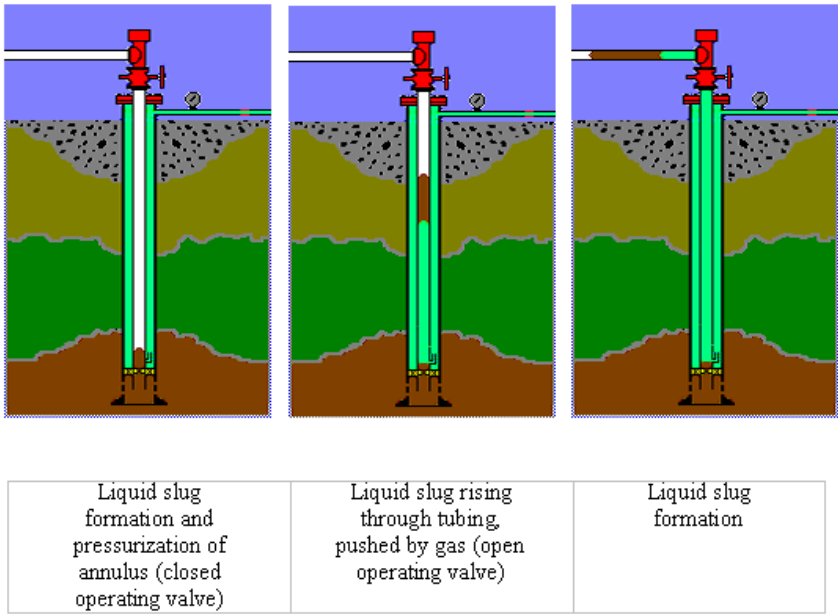

Liquid slug formation

Fig. 1 Intermittent GL cycle

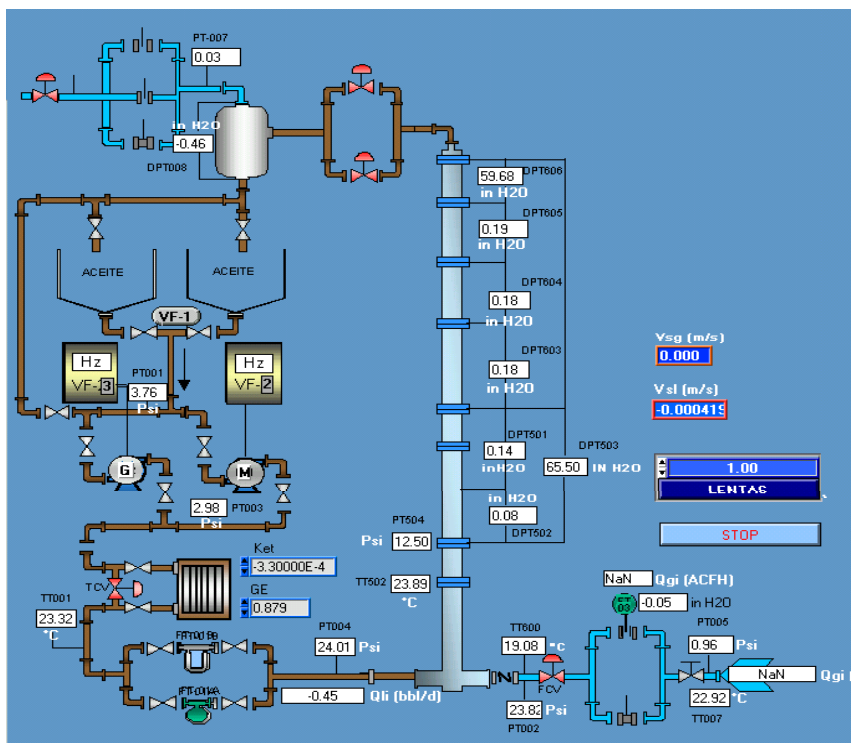

Fig. 2. Schematic diagram of the Circuit

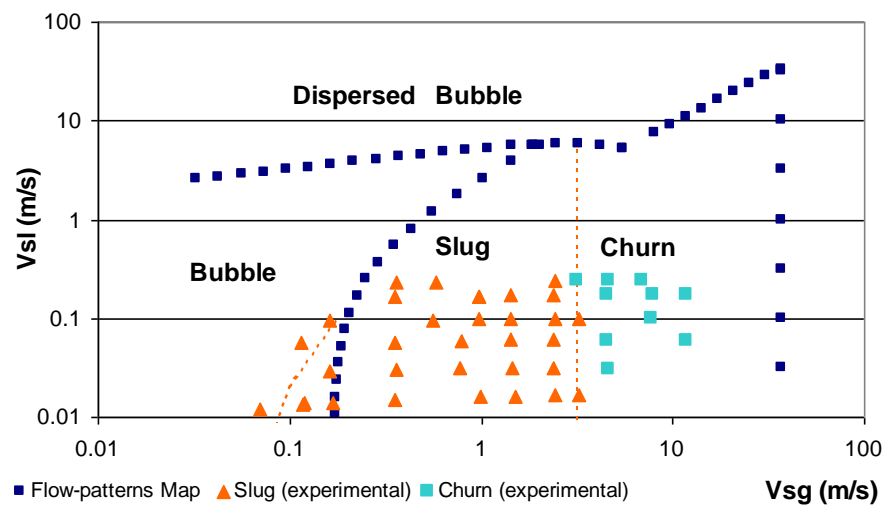


Fig. 3. Flow-patterns Map for oil 33cP-air with $90^{\circ}$ upward flow

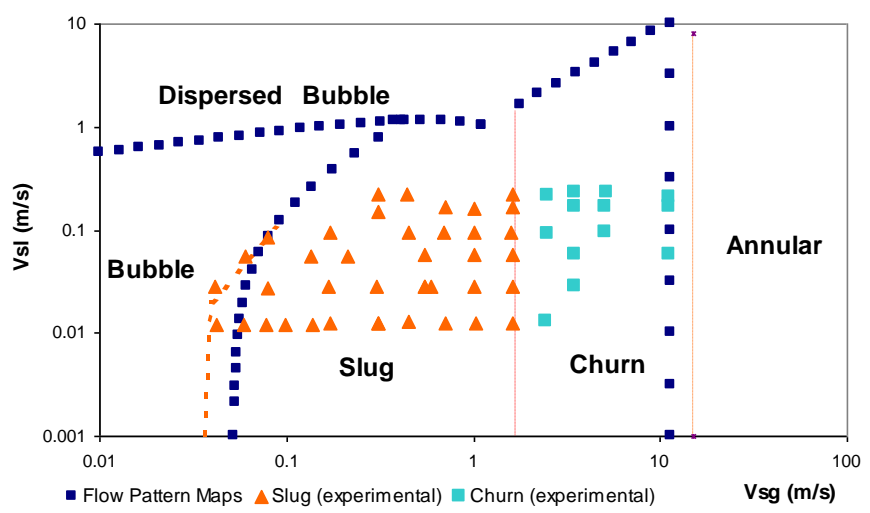

Fig. 4. Flow-patterns Map for oil 311cP-air with $90^{\circ}$ upward flow

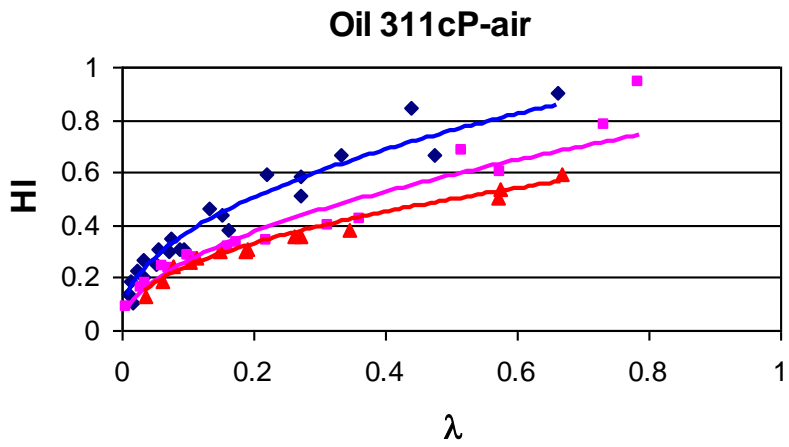

- Re1:1.65-4 - Re2:8-14 $\Delta$ Re3:24-34

\section{Oil 33cP-air}

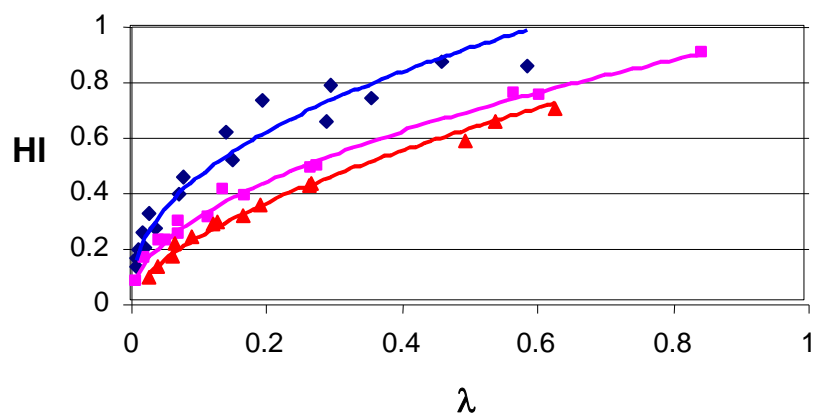

- Re1:15-45.55 - Re2:81-144 $\Delta$ Re3:241-345

Fig. 5. Dimensionless relationship of the model proposed

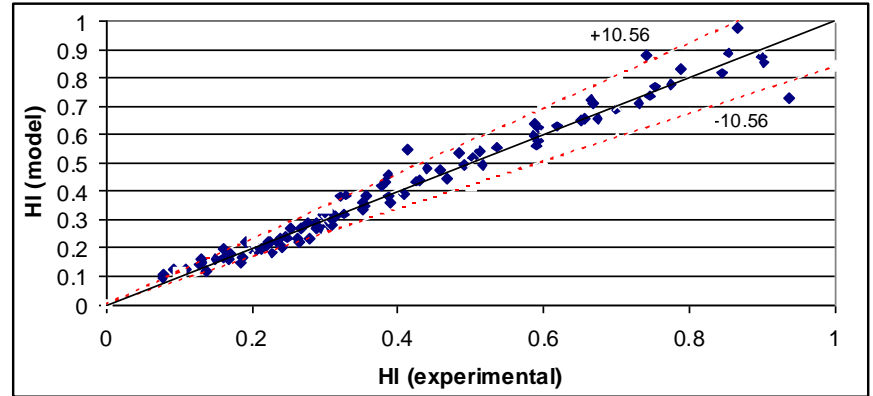

Fig. 6. Hl measured vs. model calculated

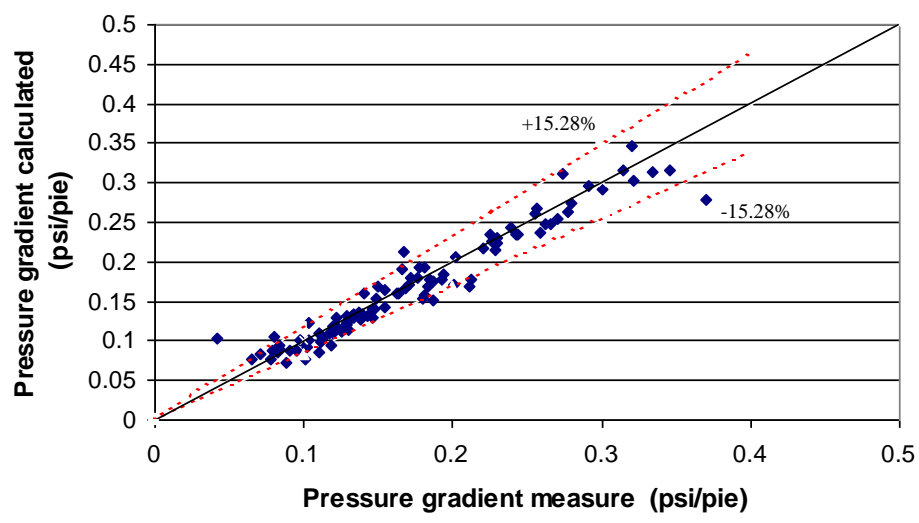

Fig. 7. Pressure gradient measured vs. model calculated 